\title{
Research on Constructing the Trinity Mechanism of Academic Feedback, Early Warning and Assistance Based on OBE Concept-- A Case Study Based on Northeast Petroleum University
}

\author{
Shuang Zhang ${ }^{1, *}$, Zhengxin Liu ${ }^{2}$, Chenyu Yang ${ }^{3}$ \\ ${ }^{1}$ School of Economics and Management, Northeast Petroleum University, Daqing, China \\ ${ }^{2}$ Academic Administration Office, Northeast Petroleum University, Daqing, China \\ ${ }^{3}$ School of Chemistry and Chemical Engineering, Northeast Petroleum University, Daqing, China \\ *Corresponding author. Email: $1987087492 @ q q . c o m$
}

\begin{abstract}
This paper aims to find a means to improve the cultivation and quality of talents for higher institutions, Research was done to construct the trinity mechanism of academic feedback, early warning and assistance. This mechanism takes the improvement of students' academic performance as its core, comprehensive academic feedback data as its statistic source, targeted early warning as its intervention method, and targeted academic assistance as its support. The mechanism, once being constructed, can reduce the occurrence rate of academic misbehaviors and prevent the trend of poor academic situation. This research was under the guidance of the OBE concept and put forward some innovative academic assistance measures.

Keywords: OBE concept, academic feedback, early warning and assistance
\end{abstract}

\section{INTRODUCTION}

Upon the introduction of the "National Standards for the Quality of Undergraduate Professional Teaching in Higher Education Institutions" (2018), China's Ministry of Education stated that the National Standards integrated the advanced concept of world higher education development and stuck to three principles of being student-centered, production-oriented and continuously improving [1]. In the "The Guideline on Accelerating the Implementation of High-Standard Undergraduate Education and Overall Improvement in Talent Cultivation Ability" (2018, also referred to as "Forty Requirements for Higher Education in the New Era"), the Ministry of Education also put forward the principles of implementing high-standard undergraduate education: "higher education institutions should take priority to moral education and foster morality and talent of students; higher education should be student-centered and pursue the all-round development of students; higher education should be result-oriented and respond to the needs of students; mechanism needs perfecting continuously; classified guidance and distinctive development should be incorporated into teaching[2]". The development of Chinese undergraduate education in the new ear requires the application of the OBE concept which features student-oriented, results-oriented, continuously improving. Having referred to the current research status and achievements at home and abroad, this research attempted to construct the trinity mechanism of academic feedback, early warning and assistance (referred to as "the trinity mechanism" in the following content), to help higher education institutions to ensure students' learning effects, have complete academic feedback, help out students with learning difficulties, and improve the quality of teaching and talents.

\section{ACADEMIC FEEDBACK MECHANISM}

The construction of academic feedback mechanism is the first and foremost step in constructing the trinity mechanism. Three parties also need considering while constructing the mechanism, including university, teacher and student. In other words, the mechanism relies on the integration of student evaluation, teacher feedback and school supervision. In this mechanism, teaching information feedback needs to be real and comprehensive, the situation of teacher's teaching and student's learning should be well understood, and problems in teaching activities are supposed to be discovered in time.

At the beginning, an academic feedback mechanism based on students' evaluation requires constructing, the function of which mainly includes two aspects: on the one hand, students can complete online evaluation of the teachers and their teaching effects anonymously within the required time; on the other hand, the teaching affairs assistant group can take feedback from students on classroom atmosphere, personal suggestion, etc.. Then it comes to the construction of an academic feedback mechanism based on teachers' feedback. Because of their leading role in the classroom, teachers can directly take feedback by assessing their classroom teaching content or the activity level and 
attendance of students, thus helping them to find out their problems in teaching. Finally, the school administrators should construct an academic feedback mechanism with the help of teaching supervisors. To achieve this, what needs to be established is a strict university-school teaching management and supervision system under which teaching administrators will inspect the classroom during the teaching process, randomly attend lectures and monitor teaching situation.

This paper takes Northeast Petroleum University as an example. In terms of the academic feedback mechanism based on students' evaluation, at the end of each term, students are organized to finish anonymous evaluations of teachers whose lectures they have attended. During the whole term's normal teaching process, teaching affairs assistants will make brief reports of the classroom situation, organize these reports in the order of teaching weeks and classify them into different schools. After information integration and data analysis, they will send the results to the dean, teaching secretary, and counselor of each school. While in the academic feedback mechanism based on teachers' feedback, every teacher has to enter class attendance record into the university's educational management system at the beginning of each class, store the accumulated statistics of students' absence, make reports on students' activity, participation, and performance in class. For illustration, the paper refers to the attendance statistics of students from each school at Northeast Petroleum University in the sixth teaching week of the second term during the 2018-2019 academic year (referring to Table 1). Furthermore, by analyzing the attendance statistics of the School of Earth Sciences in the sixth teaching week, the proportions of absence in each grade, in each day, in each session, and reasons for absence are shown in Figure 1 below:

Table 1 The attendance statistics of each school at Northeast Petroleum University in the sixth teaching week

\begin{tabular}{|c|c|c|c|c|c|}
\hline Schools & Absenteeism & $\begin{array}{c}\text { Number of } \\
\text { Compassionate } \\
\text { Leave }\end{array}$ & $\begin{array}{c}\text { Number } \\
\text { of Sick } \\
\text { Leave }\end{array}$ & $\begin{array}{l}\text { Lateco } \\
\text { mers }\end{array}$ & Total \\
\hline School of Earth Sciences & 5 & 4 & 1 & 0 & 10 \\
\hline $\begin{array}{l}\text { School of Petroleum } \\
\text { Engineering }\end{array}$ & 59 & 23 & 8 & 1 & 91 \\
\hline $\begin{array}{l}\text { School of Chemistry and } \\
\text { Chemical Engineering }\end{array}$ & 1 & 0 & 3 & 0 & 4 \\
\hline $\begin{array}{c}\text { School of Mechanical } \\
\text { Science and Engineering }\end{array}$ & 18 & 4 & 2 & 0 & 24 \\
\hline $\begin{array}{l}\text { School of Civil Engineering } \\
\text { and Architecture }\end{array}$ & 7 & 4 & 8 & 0 & 19 \\
\hline $\begin{array}{l}\text { School of Electrical and } \\
\text { Information Engineering }\end{array}$ & 20 & 2 & 1 & 0 & 23 \\
\hline $\begin{array}{l}\text { School of Computer and } \\
\text { Information Technology }\end{array}$ & 3 & 0 & 3 & 1 & 7 \\
\hline $\begin{array}{c}\text { School of Economics and } \\
\text { Management }\end{array}$ & 11 & 6 & 5 & 0 & 22 \\
\hline School of Electronic Science & 7 & 3 & 2 & 1 & 13 \\
\hline $\begin{array}{c}\text { School of Mathematics and } \\
\text { Statistics }\end{array}$ & 3 & 0 & 0 & 0 & 13 \\
\hline School of Foreign Languages & 0 & 1 & 1 & 0 & 2 \\
\hline $\begin{array}{c}\text { School of Humanities and } \\
\text { Sciences }\end{array}$ & 0 & 0 & 0 & 0 & 0 \\
\hline School of Fine Art and Music & 18 & 0 & 4 & 13 & 35 \\
\hline Total & 152 & 47 & 38 & 16 & 253 \\
\hline
\end{tabular}

Meanwhile, with the help of teaching supervisors, the university has established an academic information feedback mechanism as well. The university-school supervision system has been in full operation to ensure the authenticity and effectiveness of the teaching information feedback.

\section{ACADEMIC EARLY WARNING ANALYSIS}

Academic early warning analysis plays a pivotal role in the trinity mechanism. Under the guidance of the OBE concept, the academic feedback will be analyzed effectively to find out students with learning difficulties and reasons behind. The academic early warning analysis includes three steps. Firstly, the difficulty level of each course and the previous failure rate of examination in each 
course are assessed to find the ratio of students with learning difficulties to the total number of students, thus better understanding the overall situation of students. Secondly, the specific situation of every student with learning difficulties and the reasons for their learning difficulties will be better understood through analyzing the feedback from students' evaluation of teaching, brief reports from teaching affairs assistants, and teachers' feedback on students' attendance, classroom performance and learning effects. Here the accounting major students admitted in 2017 to the School of Economics and Management at Northeast Petroleum University are used as the subject of analysis. In the second term during the

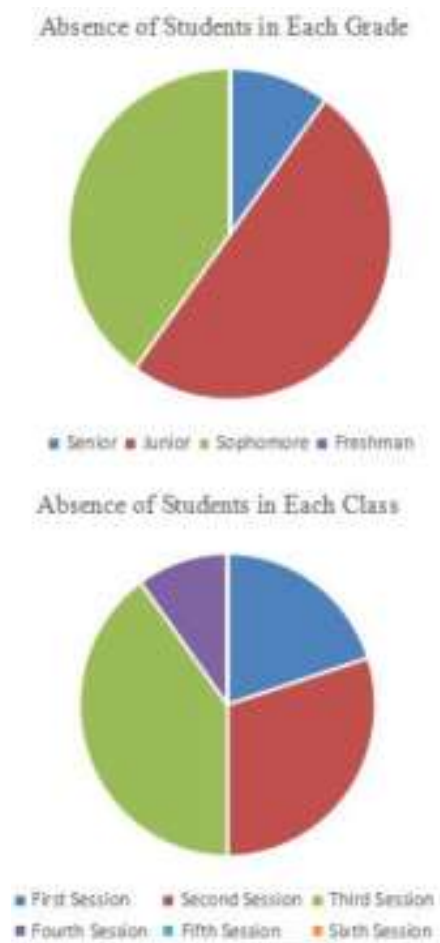

2018-2019 academic year, 86 students took the financial management course. Among them, 24 students failed in the examination of this course, and the failures rate of examination was $27.9 \%$ while the normal rate should be around 5\%. Meanwhile, brief reports from the teaching affairs assistant group concluded that this course was difficult to learn and assistance should be provided to students in the class. With regards to courses with a failure rate of about $5 \%$, the attendance statistics collected from educational administration system could help to find out students who failed in the examination, and personal help would be provided.

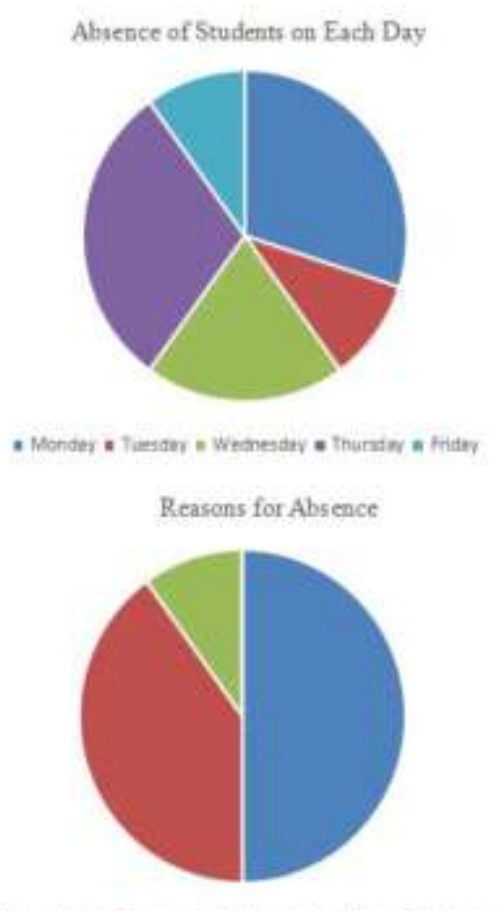

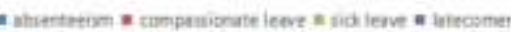

Figure 1 The attendance statistics of School of Earth Sciences in the sixth teaching week

Besides, After the implementation of the university's academic early warning policy, every academic year the educational administration office conducted a statistical analysis of students with early warning signals of blue, yellow, orange, and red and took targeted measures to provide academic assistance. By making full use of academic feedback and thorough academic early warning analysis can be conducted to make sure that academic assistance can be specific and effective enough to help rather than bother students. However, to support the implementation of academic early warning policy, universities need to establish a scientific and reasonable system and according to the actual situation, and the system needs to be upgraded to ensure that it is scientific, reasonable and flexible [3].

\section{ACADEMIC ASSISTANCE MECHANISM}

Academic assistance mechanism is another important part of the trinity mechanism. Still based on the OBE concept, general and specific academic assistance and guidance can be provided for students with learning difficulties, through the academic early warning mechanism.

First, as for direct help from fellow students, students with learning difficulties can directly ask their fellow students who perform better in university for one-on-one assistance or set up study groups with them. In doing so, students will simultaneously take to study and a good learning atmosphere can be fostered on the campus. Secondly. in the case of guidance from teachers, through offline answering room and online chat group, teachers can timely 
understand and solve questions from students. In doing so, teachers can cultivate students' learning interest and activity after-class. Thirdly, regarding curricular reform, universities should improve the teaching quality by designing more comprehensive course teaching content. Universities should also speed up teaching reform and innovation, consequently upgrading traditional teaching models. Through methods such as MOOC, conventional classroom teaching will take on a new look. Curriculum research requires deepening, the administrators concerned should construct more reasonable syllabi and more suitable curricula for students according to their needs at different development stages. Last, concerning the support of quality assurance system, the university administrators should establish or perfect the quality assurance system of education and teaching in that education is a top priority of university work. Adhering to education-centered idea, universities should establish a teaching system which integrates student, teacher, administrative office and university to deepen teaching reform.

Academic assistance should be provided timely and efficiently. Universities and their schools should act in close cooperation where the former give its principal role into full play and the latter creatively work on academic assistance, avoid inconsistency in the actual achievements of academic assistance work. The two should also make efforts to help early warned students to revoke the punishment of warning, thus reducing the number of the students being early warned.

\section{SIGNIFICANCE OF THE TRINITY MECHANISM}

On the basis of the OBE concept, the trinity mechanism integrates academic feedback, academic early warning, and academic assistance into a virtuous circle, so that teaching information feedback and data of early warning analysis can be effectively used.

For instance, Northeast Petroleum University has already constructed its trinity mechanism of academic feedback, early-warning and assistance. The relevant administrators collected teaching information feedback from teachers and teaching supervisors, and they processed data of undergraduate teaching information for the past six years collected by the teaching affairs assistants. Then they conducted surveys on students' attendance and class performance and analyzed problems existing in teaching and learning so that factors could be identified that affect the quality of students' learning in classes. Finally, they analyzed the academic status of students and gave academic early warning and assistance to target students. As a result, the passing rate of undergraduate students in Northeast Petroleum University has been increasing and the quality of students continues to improve.

The OBE concept runs through the process of integrating academic feedback, early warning analysis and academic assistance, which reflects the student-centered, result-oriented and continuously updated modern education concept. Although many kinds of researches on the teaching information feedback have been conducted in higher education institutions, adequate emphasis has not been put on the effective use of feedback results for academic early warning and assistance.

This article focuses on constructing the trinity mechanism of academic feedback, early warning, and assistance, which highlights students' academic status and helps improve the quality of teaching quality and talent cultivation.

\section{CONCLUSION}

The OBE concept meets the needs of modern education development and personal development [4]. According to the research the authors have done, the model of the trinity mechanism is shown in Figure 2. Based on the OBE concept, the construction of the trinity mechanism of academic feedback, early warning, and assistance in academic information for higher education institutions contributes to university work in three aspects. For students, the trinity mechanism can help them to understand learning outcomes and guide them to strengthen their ability to manage school work on themselves. For teachers, the student-centered concept helps them to adjust teaching strategies and solve problems in their teaching. It equally requires teachers to take supportive measures to improve the present situation of teaching, ultimately achieving the expected teaching effect. For universities and colleges, on the one hand, the trinity mechanism advances multilateral collaboration and exchanges between administration offices concerned, teachers, and counselors. Moreover, the mechanism can urge them to provide timely advice and guidance for students so that students can study diligently to fulfill the requirements of the school and professional training plan. On the other hand, the supervision and evaluation by the university administrators contribute to the continuous improvement of the trinity mechanism, and therefore, timely adjustments can be made in accordance with actual conditions to solve possible problems and cultivate talents. 


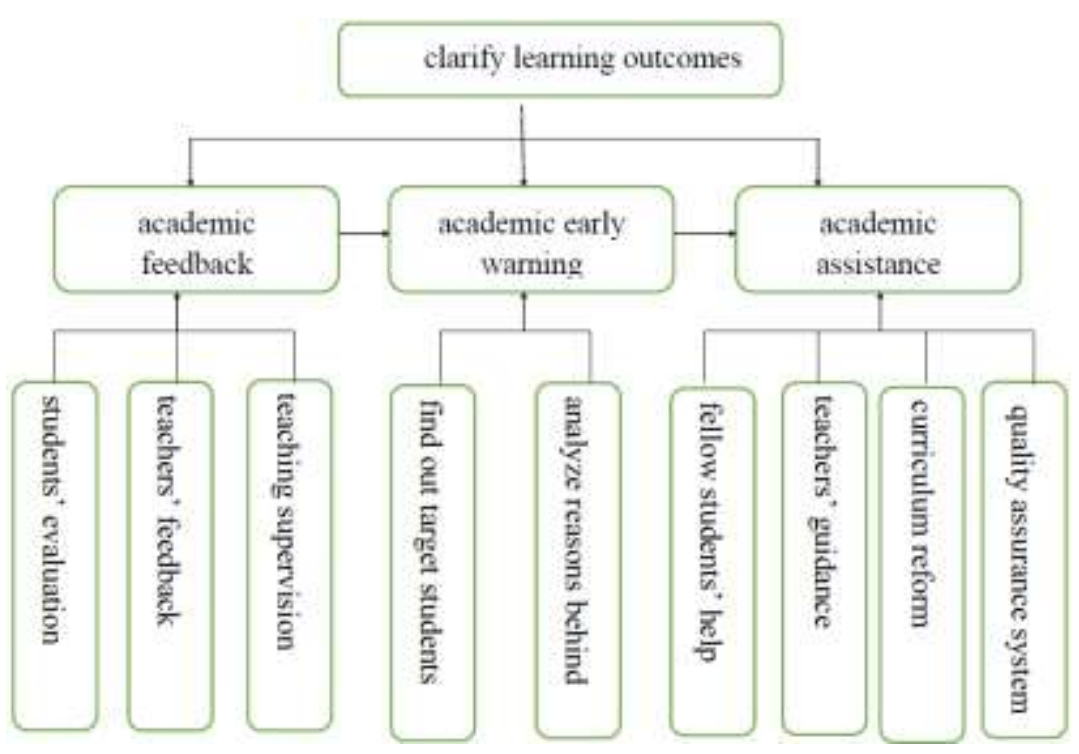

Figure 2 Trinity mechanism model based on the research of this paper.

\section{ACKNOWLEDGMENT}

Innovation and Entrepreneurship Training Program for College Students in Heilongjiang Province

\section{REFERENCES}

[1] Title: "National Standards for the Teaching Quality of Undergraduate Majors in General Colleges and Universities" [J]. Publishing Reference, 2018 (08): 74.

[2] Opinions of the Ministry of Education on accelerating the construction of high-level undergraduate education and comprehensively improving the ability of personnel training. Ministry of Education of the People's Republic of China

[3] Liu Meifeng. Research on Academic Early Warning System for Undergraduates [D]. Shaanxi Normal University, 2017.

[4] Liu Jianzhu. Results-based Education: Origin, Connotation and Framework [J]. Journal of Shenzhen Vocational and Technical College, 2019: 48. 